\title{
Is Asymptomatic Microscopic Hematuria Using a Dipstick Reliable?
}

\author{
Line S Kristiansen ${ }^{1, *}$, Knud Fabrin ${ }^{2}$, Charlotte M Skov ${ }^{3}$, Jeppe H Christensen ${ }^{4}$ \\ Department of Nephrology and Urology at Aalborg University Hospital, Hobrovej 18-22, 9100 Aalborg, \\ Denmark
}

*Corresponding Author: Line S Kristiansen, Department of Nephrology and Urology at Aalborg University Hospital, Hobrovej 18-22, 9100 Aalborg, Denmark.Email: line.kristiansen@ rn.dk

\begin{abstract}
Urine dipsticks are often used and dipstick hematuria is a frequent incidental finding. The presence of erythrocytes in the urine is considered physiological, but $\geq 3$ erythrocytes per high-power field is often defined as microscopic hematuria.

While the recommendations to evaluate patients with gross hematuria are clear, the recommendations for handling microscopic hematuria varies.

The sensitivity for hematuria on a dipstick is $97-100 \%$ and the specificity varies from 56-100\%. Despite the low specificity, a positive dipstick is seldom verified microscopically.

This study reexamined 73 out-patients, previously referred due to asymptomatic microscopic hematuria. All patients had within the previous two years undergone urological examination including cystoscopy and CTurography, without pathological findings. The participants had a fresh urine sample tested with two different multi dipsticks and then examined microscopically.

At re-examination $52(71 \%)$ patients still had hematuria on the dipstick, and of these only 36 (69\%) could be verified microscopically. The remaining $16(31 \%)$ had to few or no erythrocytes to classify it as hematuria using the microscope, giving a specificity for dipstick hematuria 51.5\%. Of the participant with $+1(\sim 25$ erythrocytes $(\mu L)$ for erythrocytes on dipstick, less than half (39\%) had hematuria when examined by microscope.

The findings indicate that a substantial number of the participants with persisting dipstick hematuria probably had been examined unnecessarily because microscopy revealed physiological hematuria $(<3$ erythrocytes/power field) and not microscopic hematuria. The finding confirms the importance of verifying a positive dipstick with microscopy before referral for urological examination.
\end{abstract}

Keywords: Microscopic Hematuria; Urine Dipstick; Adult; Reagent Strips; Urinalysis

\section{INTRODUCTION}

The excretion of erythrocytes in urine is physiological and up to $75 \%$ of healthy men have erythrocytes in their urine ${ }^{1}$. This physiological presence of erythrocytes is not fully understood, though exercise, fever, trauma and coitus are known to transiently induce hematuria.

The recommendation for asymptomatic microscopic hematuria has always been a comprehensive urological examination, because it could be due to urological malignancy. In recent years, it has become clear that the evidence for such an approach is weak ${ }^{2-4}$. Still many national guidelines ${ }^{5,6}$ recommend urological examination for patients with asymptomatic hematuria, some even suggest a 36-month follow-up if an initial urological examination is negative ${ }^{5}$.

Detection of erythrocytes on dipstick is based on oxidation of at test-strip reagent, and hematuria as well as myoglobinuria, urinary tract infection, alkaline urine and highly concentrated urine can cause this reaction. The specificity for dipstick hematuria ranges from $56-100 \%{ }^{7}$. Despite this, patients are often referred to extensive urological examination due to asymptomatic microscopic hematuria found on a dipstick, without a prior microscopic verification ${ }^{8}$. In countries which still recommend urological examination for asymptomatic microscopic hematuria, this could result in unnecessary radiation, discomfort, cost and anxiety for patients with no or only physiological amount of erythrocytes in the urine. 
The aim of the study was to identify how many patients, previously examined for asymptomatic microscopic hematuria, still had microscopically hematuria or physiological hematuria. Most patients are referred to urological examination for asymptomatic microscopic hematuria based on dipstick hematuria, without verifying it by microscope. The hypothesis was that dipstick is insufficient to differentiate between physiological hematuria and asymptomatic microscopic hematuria.

\section{Method}

This is a follow-up study of patients who had been referred with asymptomatic microscopic hematuria to the Department of Urology, Aalborg University Hospital, North Denmark Regional Hospital during the years 2012 - 2014. The participants were identified via International Classification of Diseases. A search was made in The Danish National Patient Registry, for patients with the diagnosis microscopic hematuria, DR319B. Inclusion were based on patient charts. The urological examination, the referral, the description of the cystoscopy and CT-urography, earlier admissions and out-patients contacts were reviewed. The inclusion criteria were 1) urological examination with CT-urography and cystoscopy, without abnormal findings 2) no symptoms 3) creatinine within reference interval 4) absence of leukocytes, nitrite or protein on the dipstick. The patients were asked to participate in a letter.

The participants were instructed in voiding a fresh urine sample using the correct technique. The urine was examined within 10 minutes. All samples were examined by the same laboratory technician with 25 years of experience in microscopy. Two different multi urine dipsticks (testing for erythrocytes, hemolysis, protein, glucose, $\mathrm{pH}$ and nitrite) were used, produced by either Siemens or Combur.

Ten $\mathrm{ml}$ of urine were within 10 minutes of collection centrifuged (1500 rpm for 3 minutes). One drop of the resulting sediment was colored with Sternheim And Malbins color-fluid and examined using 400x magnification. A minimum of 10 high-power fields were used.

The definition of microscopic hematuria varies but this study used the most common definition; $\geq 3$ erythrocytes per high-power field ${ }^{5,6}$. Hematuria on a dipstick was defined as $\geq+1$ $(\sim 25$ erythrocytes $/ \mu \mathrm{L})$ for Siemens and $\geq+2(\sim 25$ erythrocytes $/ \mu \mathrm{L}$ ) for Combur, according to the product information. The use of anticoagulants was noticed.
The results of the testing from the two producers were comparable and because Siemens is the most used dipstick among general practitioners in North Jutland, Denmark, the dipstick from Siemens was chosen to be point of reference.

Sensitivity was compared using Chi-squared test with a prespecified, two-sided significance level of 0.05 . Statistical analysis was preformed using SPSS ver 23.

\section{RESUltS}

Six-hundred potential participants were identified via The Danish National Patient Registry, International Classification of Diseases, and after reviewing the patients' medical records, 406 were excluded based on the presence of urogenital symptoms, gross hematuria or abnormal findings (CT-urography or cystoscopy). One-hundred-ninety-four were invited of which 79 agreed to participate, resulting in a response rate of $41 \%$. Six participants had cystitis, hemospermia or proteinuria and therefore excluded. Thus, a total of 73 participants were included in the study, 36 men and 37 women with a mean age of 58 and 60 years, respectively.

Fifty-two of 73 (71\%) had hematuria on dipstick. Thirty-six of the $52(69 \%)$ were confirmed by microscopic examination while 16 out of the $52(31 \%)$ had to few or no erythrocytes to classify it as hematuria. Only 1 of the 16 had no erythrocytes at all. Four participants had trace on urine dipstick and a positive microscopy. The results are outlined in Table 1.

Table1. Patients priorly examined for microscopic hematuria with negative results, had urine reexamined with urine dipstick and microscopy

\begin{tabular}{|ll|l|l|l|l|l|l|}
\hline \multicolumn{2}{|c|}{ Microscope } & \multicolumn{5}{|c|}{ Dipstick for erythrocytes } \\
\hline & \multicolumn{2}{|c|}{$\begin{array}{l}\text { Negative } \\
\text { Trace } \\
+/-\end{array}$} & +1 & +2 & +3 & Total \\
\hline $\begin{array}{l}\text { Physiological } \\
\text { hematuria } \\
\text { Ery/HPF }\end{array}$ & 2 & & 15 & 11 & 5 & 0 & 33 \\
\hline $\begin{array}{l}\text { Microscopic } \\
\text { hematuria } \\
\text { Ery/HPF }\end{array}$ & $\geq \mathbf{3}$ & 0 & 4 & 7 & 20 & 9 & 40 \\
\hline
\end{tabular}

HPF: High power field

We found that dipstick urine analysis sensitivity was $90 \%$ and specificity $51.5 \%$.

There is a significant reciprocal relation between the degree of hematuria and the risk of dipstick hematuria that cannot be confirmed by 
microscopy $[\mathrm{p}=0.001]$. Sixty-one $\%$ of participants with +1 erythrocytes on dipstick had to few or no erythrocytes to classify it as microscopic hematuria. All participant with +3 erythrocytes on dipstick had microscopic hematuria when microscopically examined.

In this study, no associations between hematuria and the use of anticoagulants, gender, age or hemolysis on the dipstick were found (data not shown).

\section{DISCUSSION}

Hematuria is physiological, and Sanders et al ${ }^{1}$ reported that $74 \%$ of 725 healthy males had erythrocytes in the urine when microscopically examined. The prevalence of microscopic hematuria (more erythrocytes than physiological expected), is $2-13 \%{ }^{9}$ in the general population. Our study in patients diagnosed asymptomatic microscopic hematuria with negative evaluation, found that $71 \%$ (52) of the participants still had dipstick hematuria upon reexamination in line with a previous follow-up study of 191 patients with unexplained microscopic hematuria ${ }^{10}$.

Multi-dipstick is still frequently used and dipstick hematuria is often an incidental finding. In this study, a substantial number of patients with dipstick hematuria had physiological hematuria and not microscopic hematuria. We found that 16 out of 52 (31\%) with dipstick hematuria had to few or no erythrocytes to classify it as hematuria when microscopically examined. Of participants with +1 erythrocytes on dipstick, the number was even higher $(61 \%)$. A similar study ${ }^{11}$ found that $21 \%$ of their healthy participants had positive dipstick but to few or no erythrocytes to classify it as hematuria, while another study ${ }^{8}$, with lower cutoff-values for hematuria, found this figure to be $15 \%$.

The numbers above suggest that a considerable part of the participants in this study at the time of referral for urological examination had physiological hematuria and not microscopic hematuria, which make the examinations preformed unnecessary. Thus, unnecessary radiation, discomfort, cost and anxiety for patients might have been avoided. This would count for the 16 participants with physiological hematuria, but also the 21 participants with no hematuria at the time of reexamination (ref, this study).

Guidelines recommend microscopically confirmation of dipstick hematuria before referral for urological examination ${ }^{12}$. None-the less a study ${ }^{13}$ in 2010 found that only $41 \%$ of patients referred with the diagnosis of asymptomatic microscopic hematuria had microscopic urine analysis performed before referral. Furthermore, only $24 \%$ of the referred patients had $\geq 3$ erythrocytes/high power field.

The specificity of hematuria is known to be low. A systematic review ${ }^{7}$ from 2006 identified 18 studies dealing with the specificity of dipstick hematuria which varied between $56-100 \%$. The studies were mainly small cohorts with a lack of clinical data on the patients. The wide variation in reported specificity might be explained by the considerable disagreement on the definition of hematuria and method of microscopy. See Table2.

This study found a specificity of $51.5 \%$, which is lower than reported previously (ref, systematic review). The differences between the results in this study compared with the abovementioned studies are partly caused by selection. The cohort in this study was highly selected, to ensure that it represented a group of healthy patients with verified asymptomatic microscopic hematuria. The inclusion criteria in our study was a thorough examination within 2 years with no abnormal findings and no urogenital symptoms. Other studies ${ }^{8,14-17}$ included participant regardless of medical history, urological examinations and symptoms.

It is of importance that studies regarding asymptomatic microscopic hematuria verify dipstick hematuria microscopically before enrolling patients. If not, there is a risk of including a considerable number of patients with physiological hematuria. This would mask a potential connection between microscopic hematuria and pathology. However, such a connection is controversial. Whereas gross hematuria needs further extensive examinations to exclude or confirm serious pathology, the importance of a thorough evaluation is uncertain when it comes to asymptomatic microscopic hematuria. During the past, it has been discussed whether asymptomatic microscopic hematuria can be a sign of underlying pathology. In recent years, it has become clear that the evidence for this is weak ${ }^{2,3}$. The most recent study ${ }^{4}$ found that the malignancy rate for patients referred with asymptomatic microscopic hematuria was 1,5 $\%$, and the cancers were all detected in patients aged $\geq 60$ 
Table2. Studies dealing with the specificity of dipstick hematuria

\begin{tabular}{|c|c|c|c|c|c|}
\hline Reference & Study & Participants & $\begin{array}{l}\text { Method of } \\
\text { Microscopy }\end{array}$ & $\begin{array}{l}\text { Definition of } \\
\text { hematuria }\end{array}$ & Results \\
\hline $\begin{array}{l}\text { Br J Gen Pract. } \\
1990^{11}\end{array}$ & $\begin{array}{l}\text { Prospective } \\
\text { study }\end{array}$ & $\begin{array}{l}58 \text { men attending } \\
\text { health check }\end{array}$ & $\begin{array}{l}\text { Within } 2 \text { hr. } \\
\text { Centrifuge }\end{array}$ & $\begin{array}{l}\text { Dipstick: } \\
\geq+1 \\
\text { Microscopy: } \\
\geq 2 \text { Ery/HPF }\end{array}$ & $\begin{array}{l}\text { False positive: } 21 \% \\
\text { False negative: } 0 \%\end{array}$ \\
\hline $\begin{array}{l}\text { Ugeskr Laeger. } \\
1996^{8}\end{array}$ & $\begin{array}{l}\text { Prospective } \\
\text { study }\end{array}$ & $\begin{array}{l}122 \text { inpatients and } \\
31 \text { healthy hospital } \\
\text { personal }\end{array}$ & $\begin{array}{lr}\text { Within } 2 & \mathrm{hr} \\
\text { Centrifuge } & \text { Fuch } \\
\text { Rosentahl- } & \\
\text { counting } & \text { chamber }\end{array}$ & $\begin{array}{l}\text { Dipstick: } \\
>5 \text { Ery/ } \mu \mathrm{L} \\
\text { Microscope: } \\
>3 \text { Ery/ } \mu \mathrm{L} \\
(1-2 \text { Ery/HPF })\end{array}$ & $\begin{array}{l}\text { False positive: } 15 \% \\
\text { False negative: } 3 \%\end{array}$ \\
\hline $\begin{array}{lll}B r & J & \text { Urol } . \\
1993^{17} & \end{array}$ & $\begin{array}{l}\text { Prospective } \\
\text { study }\end{array}$ & \begin{tabular}{|lr} 
1000urologic & out \\
patients with & no \\
regard & of \\
symptoms & and \\
diagnoses & \\
\end{tabular} & $\begin{array}{lr}\text { Unspun } & \text { Kova } \\
\text { Glasstic } & \text { Slide- } \\
\text { counting } & \text { chamber }\end{array}$ & $\begin{array}{l}\text { Dipstick: } \\
\geq \text { trace Microscope: } \\
\geq 5 \text { Ery } / \mu \mathrm{L}\end{array}$ & $\begin{array}{l}\text { False positive: } 9.8 \% \\
\text { False negative: } 3 \%\end{array}$ \\
\hline $\begin{array}{ll}\text { Clin } & \text { Chem. } \\
1987^{15} & \end{array}$ & $\begin{array}{l}\text { Prospective } \\
\text { study }\end{array}$ & $\begin{array}{ll}315 & \text { inpatients, } \\
\text { with } & \text { no } \\
\text { UVI } & \end{array}$ & $\begin{array}{l}\text { Within } 2 \mathrm{hr} \\
\text { Centrifuge }\end{array}$ & $\begin{array}{l}\text { Dipstick: } \\
\geq \text { trace Microscope: } \\
\geq 1 \text { Ery/HPF and } \\
\geq 4 \text { Ery/HPF }\end{array}$ & $\begin{array}{l}\text { False positive: } 6 \% \\
\text { Specificity: } \\
194.1 \%(\geq 1 \quad \text { ry/HPF }) \\
90.2 \%(\geq 4 \text { ry/HPF })\end{array}$ \\
\hline $\begin{array}{l}\text { Pathology. } \\
1995\end{array}$ & $\begin{array}{l}\text { Prospective } \\
\text { study }\end{array}$ & \begin{tabular}{|lr}
2928 & inpatients \\
and outpatients. 10 \\
$\%$ & catheter \\
specimen & urine. \\
$9.2 \%$ & with UVI
\end{tabular} & $\begin{array}{l}\text { Unspun } \\
\text { Calibrated } \\
\text { counting chamber } \\
\text { (haemocytometer) }\end{array}$ & $\begin{array}{l}\text { Dipstick: } \\
\geq \operatorname{trace}(>10 \text { Ery } / \mu \mathrm{L}) \\
\text { Microscope: } \\
>10 \text { Ery/ } / \mu \mathrm{L}\end{array}$ & $\begin{array}{l}\text { False positive: } \\
18-30 \% \text {. } \\
\text { False negative: } \\
16-21 \% \text {. }\end{array}$ \\
\hline \begin{tabular}{|l} 
J Urol. $1984^{16}$ \\
\end{tabular} & \begin{tabular}{|l|} 
Double- \\
blinded \\
prospective \\
study
\end{tabular} & \begin{tabular}{|l}
1346 patients with \\
previously existing \\
medical conditions \\
under medical \\
control, \\
asymptomatic
\end{tabular} & $\begin{array}{l}\text { Average } 50 \mathrm{~min} \text {. } \\
\text { Centrifuge } \\
\text { Sternheimer- } \\
\text { Malbin } \\
\text { stain solution }\end{array}$ & $\begin{array}{l}\text { Dipstick: } \\
\geq \text { trace } \\
\text { Microscope: } \\
>2 \text { Ery/HPF }\end{array}$ & $\begin{array}{ll}\text { False } & \text { positive: } \\
16.4 \% & \\
\text { False } & \text { negative: } \\
0.9 \% & \end{array}$ \\
\hline $\begin{array}{l}\text { Health Technol } \\
\text { Assess. } 2006^{7}\end{array}$ & $\begin{array}{l}\text { Systematic } \\
\text { review }\end{array}$ & 18 studies & & $\begin{array}{l}\text { Average likelihood } \\
\text { ratio: } \\
\text { +LH5.58(3.39,7.91) } \\
\text { Median likelihood } \\
\text { ratio: } 6 \text {-LH } 0.24 \\
(0.09-0.28)\end{array}$ & 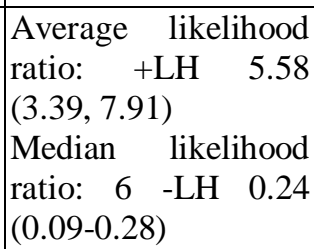 \\
\hline This study & $\begin{array}{l}\text { Follow-up } \\
\text { study }\end{array}$ & \begin{tabular}{|lr} 
73patients, priorly \\
examined & for \\
microscopic & \\
hematuriar with \\
negative results
\end{tabular} & $\begin{array}{l}\text { Within } 10 \text { min. } \\
\text { Centrifuge } \\
\text { Sternheimer- } \\
\text { Malbins } \\
\text { stain solution }\end{array}$ & $\begin{array}{l}\text { Dipstick: >+1 } \\
\text { Microscope: } \\
>2 \text { Ery/HPF }\end{array}$ & $\begin{array}{l}\text { False positive: } 31 \% \\
\text { False negative: } 19 \% \\
\text { Sensitivity:90\% } \\
\text { Specificity: } 51.5 \%\end{array}$ \\
\hline
\end{tabular}

HPF: High power field UVI: Urinary tract infection

Still, many countries ${ }^{12,18}$ recommend examination of asymptomatic microscopic hematuria, some even recommend 36-month follow-up for patients with negative evaluation. Especially the latter is controversially. A recent follow-up study of patients with asymptomatic microscopic hematuria with negative evaluation showed that there was no significant differences in incidence of malignancy between participant with asymptomatic microscopic hematuria and no hematuria ${ }^{19}$.

One of the first countries to omit the urological examination of patients with asymptomatic microscopic hematuria was Sweden ${ }^{3}$ in 2003.
Testing for microscopic hematuria should be targeted, based on relevant clinical or biochemical information. To avoid unnecessary "noise" for clinicians and to protect the patients against unwarranted referrals and pathologization erythrocytes should be removed from the multi-dipsticks and instead be produced as a single stick. A dipstick negative for hematuria can furthermore provide the false security of no pathology. Urogenital malignancy has an intermittent and variated bleeding pattern ${ }^{19}$. This is the reason that all reported cases of gross hematuria, should be referred even if their dipstick is negative for erythrocytes. A negative dipstick neither shall 
nor can be a deciding factor when considering referring a patient for further urogenital evaluation. It should be based on reports of gross hematuria and other relevant symptoms. The risk is that clinicians overlook underlying pathology because dipstick hematuria can trigger the clinicians to explore in the patients' urogenital symptoms, which otherwise would have been missed.

\section{CONCLUSION}

Seventy-one percent of patients previously referred for asymptomatic microscopic hematuria and without pathological findings at urological examination still had persisting dipstick hematuria. Only $69 \%$ could be verified microscopically. The study suggest that dipstick hematuria should be verified by microscope before referral for urological examination in countries which still recommend examination for asymptomatic microscopic hematuria.

\section{REFERENCES}

[1] SANDERS C. Clinical urine examination and the incidence of microscopic haematuria in apparently normal males. Practitioner. 1963;191:192-197.

[2] Boman H, Hedelin H, Holmang S. The results of routine evaluation of adult patients with haematuria analysed according to referral form information with 2-year follow-up. Scand J Urol Nephrol. 2001;35(6):497-501.

[3] Malmstrom PU. Time to abandon testing for microscopic haematuria in adults? BMJ. 2003;326(7393):813-815.

[4] Elmussareh M, Young M, Ordell Sundelin M, Bak-Ipsen CB, Graumann O, Jensen JB. Outcomes of haematuria referrals: Two-year data from a single large university hospital in denmark. Scand J Urol. 2017;51(4):282-289.

[5] Wollin T, Laroche B, Psooy K. Canadian guidelines for the management of asymptomatic microscopic hematuria in adults. Can Urol Assoc J. 2009;3(1):77-80.

[6] Sharp V.J., Barnes K.T., Erickson B.A. Assessment of asymptomatic microscopic hematuria in adults. . Updated 2013. Accessed 11,88 .

[7] Rodgers M, Nixon J, Hempel S, et al. Diagnostic tests and algorithms used in the investigation of haematuria: Systematic reviews and economic evaluation. Health Technol Assess. 2006;10(18):iii-iv, xi-259.
[8] Flyger HL, Bjerrum PJ, West-Nielsen E, Bodker AW, Meyhoff HH. Usefulness of urine dipsticks in the diagnosis of microscopic hematuria. Ugeskr Laeger. 1996;158(47):67596762.

[9] Tomson C, Porter T. Asymptomatic microscopic or dipstick haematuria in adults: Which investigations for which patients? A review of the evidence. BJU Int. 2002;90(3):185-198.

[10] Howard RS, Golin AL. Long-term followup of asymptomatic microhematuria. J Urol. 1991; 145(2):335-336.

[11] Dowell AC, Britton JP. Microhaematuria in general practice: Is urine microscopy misleading? Br J Gen Pract. 1990;40(331):6768.

[12] Sharp VJ, Barnes KT, Erickson BA. Assessment of asymptomatic microscopic hematuria in adults. Am Fam Physician. 2013;88(11):747-754.

[13] Rao PK, Gao T, Pohl M, Jones JS. Dipstick pseudohematuria: Unnecessary consultation and evaluation. J Urol. 2010;183(2):560-564.

[14] Holland DJ, Bliss KJ, Allen CD, Gilbert GL. A comparison of chemical dipsticks read visually or by photometry in the routine screening of urine specimens in the clinical microbiology laboratory. Pathology. 1995;27(1):91-96.

[15] Grinstead GF, Scott RE, Stevens BS, Ward VL, Wilson DM. The ames clinitek 200/multistix 9 urinalysis method compared with manual and microscopic methods. Clin Chem. 1987;33(9):1660-1662.

[16] Mariani AJ, Luangphinith S, Loo S, Scottolini A, Hodges CV. Dipstick chemical urinalysis: An accurate cost-effective screening test. J Urol. 1984;132(1):64-66.

[17] Gleeson MJ, Connolly J, Grainger R, McDermott TE, Butler MR. Comparison of reagent strip (dipstick) and microscopic haematuria in urological out-patients. Br J Urol. 1993;72(5 Pt 1):594-596.

[18] Davis R, Jones JS, Barocas DA, et al. Diagnosis, evaluation and follow-up of asymptomatic microhematuria (AMH) in adults: AUA guideline. J Urol. 2012;188(6 Suppl):2473-2481.

[19] Madeb R, Golijanin D, Knopf J, et al. Longterm outcome of patients with a negative workup for asymptomatic microhematuria. Urology. 2010;75(1):20-25

Citation: Line S Kristiansen, Knud Fabrin, Charlotte M Skov \& Jeppe H Christensen. Is Asymptomatic Microscopic Hematuria Using a Dipstick Reliable?. ARC Journal of Urology.2017; 2(2):31-35. doi: dx.doi.org/10.20431/2456-060X.0202005

Copyright: () 2017 Authors. This is an open-access article distributed under the terms of the Creative Commons Attribution License, which permits unrestricted use, distribution, and reproduction in any medium, provided the original author and source are credited. 